\title{
Decomposition analysis of modern contraceptive use among currently married women in Ethiopia: EDHS 2000-2016
}

\section{Endalekachew Worku Mengesha}

Bahir Dar University College of Medical and Health Sciences

Desalegne Amare Zelellw ( $\nabla$ desalegnezelellw@gmail.com )

Haile Mekonnen Fenta

Bahir Dar University College of Science

\section{Research}

Keywords: contraceptive, women, married, decomposition

Posted Date: January 14th, 2020

DOI: https://doi.org/10.21203/rs.2.20723/v1

License: (c) (i) This work is licensed under a Creative Commons Attribution 4.0 International License. Read Full License 


\section{Title page}

Title: Decomposition analysis of modern contraceptive use among currently married women in Ethiopia: EDHS 2000-2016.

Endalkachew Worku Mengesha ${ }^{1}$

School of Public Health, College of Medicine and Health Science, Bahir Dar University

Desalegne Amare Zelellw²

School of Health Science, College of Medicine and Health Science, Bahir Dar University

Haile Mekonnen Fenta ${ }^{3}$

College of Science, Bahir Dar University

Corresponding author

Desalegne Amare Zelellw

school of Health Science, College of Medicine and Health Science, Bahir Dar University

desalegnezelellw@gmail.com 


\section{Abstract}

Background: Contraceptive use is an essential care to reduce maternal and child mortality by preventing unwanted pregnancy and abortion. Despite different studies are conducted related to family planning services, the difference in characteristics of changes and the effects of population behavior were not well addressed. Therefore, this study aimed to assess the trend of modern contraceptive use, and investigate the difference in characteristics of changes and the effects of population behavior in the use of modern contraceptives.

Methods: The data source was from four consecutive Ethiopia demographic and health surveys of women with complete interview file from 2000 -2016. The total sampled married women considered for this study were 9,380 (2000), 8,644(2005), 10,204(2011) and 9,824 (2016). Descriptive analysis was applied to describe socio-demographic variables, fertility desires, and media exposure. Multivariate decomposition analysis was carried out to investigate the changes in the characteristics and effects of population behavior in modern contraceptive use.

Results: The trend of modern contraceptive use was steadily increased from $6 \%$ in 2000 to 35\% in 2016. The overall decomposition change in modern contraceptive use among married women was $8.3 \%$ (2000 to 2016); due to differences in characteristics. The differences in effects accounted for $86 \%$ of the observed changes in the use of modern contraceptives in phase I (from 2000 to 2005). In phase II (2005-2011) the difference effect was $91 \%$ among women using a modern contraceptive. Similarly, in phase IV (2000-2016), the observed difference was $92 \%$. Variables contribute to the change are religion, residence, women's and partners' education, women's and partners' occupation, head of household, history of abortion and media of exposure.

Conclusion: The trend of modern contraceptive use was steadily increased in all surveys. Although the utilization of modern contraceptives increased by currently married women, the proportion was less than that of the national target. The change in contraceptive use was due to the change in characteristics and population health behavior. This composition characteristics change and the health behavior of the population is driven by the residence, women and partners' education, head of the household, media exposure and wealth Index.

Keywords: contraceptive, women, married, decomposition 


\section{Plain English summary}

Contraceptive use is a universal practice to prevent too early pregnancy, too old pregnancy, inadequate space births (when births come too early or less than two years apart) and too many pregnancies which are risks for maternal mortality and morbidity. The modern contraceptive method is important to prevent adverse health outcomes for both the mothers and the fetuses. Unmet need for family planning is more than $10 \%$ worldwide. In Africa, this increased by half as compared to the global figure. Sub-Sahara African countries indicated that the modern contraceptive prevalence rate among married women is increasing. Ethiopia is one of the SubSaharan countries which has a consistent increase in modern contraceptive practice although the actual achievement is less than the national target.

The trend of modern contraceptive use in Ethiopia is steadily increasing in all DHS surveys. We observed that there are visible differences in modern contraceptive prevalence rates across the regions in Ethiopia. The highest rate has been observed in Addis Ababa (50\%), Amhara region (47\%) and south nation nationality and people region (40\%), while the lowest rate has been seen in the Somalia region. Modern contraceptive use among married women is high in the age ranges from 20-24 and 25-29 years.

Our study had identified that the change in characteristics of modern contraceptive use and health behavior of the population is determined by several factors such as the residence of participants, women's and partners' education, head of the household, media exposure and wealth Index. 


\section{Background}

Contraceptives are used by the majority of married women in almost all regions of the world. In 2017, about $63 \%$ of women were using any type of contraception. This contraceptive use was above $70 \%$ in Europe, Latin America and the Caribbean, and Northern America, but less than $25 \%$ in Middle and Western Africa (1-3). Approximately, 58\% of married women were using a modern method of family planning, this comprised of $92 \%$ of all contraceptive users(1). Global estimate of 800 million married women are expected to be using contraception in 2030, and growth in the number of contraceptive users can be uneven across regions. The global number of married women using contraception is planned to rise by 20 million, from 758 million in 2015 to 778 million in 2030(4).

More than one in ten married women worldwide have an unmet need for family planning, and in Africa, one in five women have an unmet need for family planning(1). Other evidence shows that the unmet need for modern methods ranges from $10.2 \%$ to $39.9 \%$ in Nicaragua and the democratic republic of Congo, respectively. The modern contraceptive prevalence rate (mCPR) is as lowest (2.6\%) in Somalia and as the highest (77.4\%) in Nicaragua(5). According to the DHS report of Sub Sahara Africa countries indicated that mCPR among married women was 2.3\% in Ethiopia (2005-2011), 2.4\% in Malawi (2004-2010), and a dramatic 6.9\% in Rwanda (2005-2010), (6).

Although the Ethiopian government planned to increase contraceptive prevalence rate to $55 \%$ in 2020, Ethiopia demographic and health survey(EDHS) (7) report indicates below the target (41\%) in 2019(8). An improvement in mCPR had led to a drop in the total fertility rate (TFR) from 7.7 to 4.1. However, there is a huge TFR disparity between regions in Ethiopia from 7.2 in the Somali region to 1.8 in Addis Ababa $(7,9)$. Several factors affect the use of modern methods in Ethiopia; place of residence, wealth index, educational status (10-12), desire and number of children alive $(13,14)$. Women living in an urban area, in the higher wealth index and secondary and above educational status had a contribution to use modern contraceptive than other women (15).

Although modern contraceptive use among married women in Ethiopia has been increased consistently from 2000 to 2016, the change does not extend to the expected level $(12,16)$. 
Therefore, this study aimed to investigate major factors contributing to the use of modern contraceptives and characteristics change in the population in the last twenty years. Also, this study helps to describe the trend of modern contraceptive use, and examine the difference in characteristics of changes and the effects of population behavior in the use of modern contraceptives from EDHS 2000 to 2016.

\section{Methods}

\section{Data sources}

This study used four consecutive EDHS data of women with a complete interview (IR) file from 2000 -2016. The EDHS is a national survey collected from nine provinces in Ethiopia (7, 17-19) using a cross-sectional study design. Samples were proportionally allocated for each region based on its population size. In EDHS surveys, the data were collected from households using women (age 15-49 years) interviewing questionnaires. The survey had a hierarchical data structure (i.e household, women and child). Family planning indicators in EDHS surveys include knowledge of contraception, source of supply, acceptability, use, attitudes toward contraception, intention to use in the future, reasons for nonuse, informed choice, and exposure to media messages about family planning, and a variety of related topics. The four datasets have comparable information on household characteristics and modern contraceptive use at the time of the survey.

\section{Variables}

\section{Dependent Variable}

The dependent variable for this study is women who currently use any modern method. The variable was categorized dichotomously as a "Yes/No" variable.

\section{Independent Variables}

Socio-demographic variables: include age, religion, region, residence, women's education, partner's education, women's occupation, partner's occupation, number of living children and wealth index.

Fertility preference and media exposure: birth order, the ideal number of children, history of abortion, decision making towards family planning use and media exposure. 


\section{Operational Definitions}

Modern contraceptive use: Respondents who were currently using a modern contraceptive methods like oral contraceptive pill, female sterilization, Intra-uterine device (IUD), injectable, implants/Norplant, male condom, locational amenorrhea method, emergency contraceptive and standard day methods were categorized as "Yes", whereas withdrawal and periodic abstinence were categorized as "No" response.

The number of living children: the sum of the number of children alive at the time of the survey who were given birth by women in the sample(20). In this study, the variable is categorized as: no living children, 1-5 and six and above children

Birth order: The order number of the births from the first to last(20) and classified as: no children, 1-3, 4-6, seven and above and non-numeric.

The ideal number of children: women and men who declare, that if they could go back to the time when they did not have any children and could choose exactly the number of children to have in their whole life, a specific number of children.

Media exposure: women exposed to specific media (newspaper or magazine, television, and radio) on a weekly base classified as "Yes", else "No".

\section{Statistical analysis}

The outcome variable was coded as a binary variable (use 1 and not use 0 ) and the data analysis was performed using stata 14 . The data analysis part includes three important stages, The first descriptive statistics and trends were analyzed in selected recoded background variables among all currently married women using contraceptive in the five years preceding each survey. Second binary logistic regression analysis was carried out to identify factors associated with modern contraceptive use. Third, multivariate decomposition procedures were implemented to examine the extent to which each selected covariate contributed to the observed increment in modern contraceptive use $(6.3 \%, 13.9 \%, 27.3 \%$, and $35.3 \%)$. This multivariate decomposition provides a way to analyze differences in the outcome between two groups or, for instance, between two points of time (like 2000 and 2016 survey years). The decomposition procedure divides the total increase in modern contraceptive use into two portions: these can be attributed to the change in composition (endowments) and the change in the effect of these indicators (coefficients).

Descriptive analysis was applied to describe socio-demographic variables, fertility desires, and media exposure. Data were presented using texts, tables, and figures. Besides, multivariate 
decomposition analysis was done to identify the cause of changes in the use of modern contraceptives. The changes in population composition and population behavior related to contraceptive use (effect) are analyzed by using a decomposition approach.

The observed changes in modern contraceptives were explained by using the decomposition approach. The conventional Blinder-Oaxaca(22, 23) decomposition analysis is based on two linear regression models that are fitted separately for the groups A and B:

$$
\begin{aligned}
& \bar{Y}_{A}-\bar{Y}_{B}=\mathrm{F}\left(\mathrm{X}_{\mathrm{A}} \beta_{\mathrm{A}}\right)-\mathrm{F}\left(\mathrm{X}_{\mathrm{B}} \beta_{\mathrm{B}}\right) \quad \text { (Multivariate Decomposition) } \\
& =\underbrace{\overline{F\left(X_{A} \beta_{A}\right)-F\left(X_{B} \beta_{A}\right)}}_{\text {Endowment }}+\underbrace{\overline{F\left(X_{B} \beta_{A}\right)-F\left(X_{B} \beta_{B}\right)}}_{\text {Coefficient }}
\end{aligned}
$$

According to Blinder and Oxaca decomposition analysis model, we used the following equations:

Where $\bar{Y}_{A}-\bar{Y}_{B}$ is the mean outcome difference, and $\bar{X}_{A}$ and $\bar{X}_{B}$ are mean vectors of the estimated coefficient vectors $\beta_{A}$ and $\beta_{B}$ for the two groups. In both equations, the first term on the right-hand side displays the difference in the outcome variable between the two groups due to differences in observable characteristics, whereas the second term shows the differential that is due to differences in coefficient estimates.

The change in modern contraceptive use is obtained from change in population structure and change in health behavior over the two time periods (or groups) from 2000 to 2005(18, 19), 2005 to $2011(19,20), 2011$ to $2016(10,20)$ and 2000 to $2016(10,18)$. The decomposition analysis was applied by using the national DHS dataset of Ethiopian women with completed interview (ETIR) files. This method was assumed that there is a change in proportional of modern contraceptive uses by currently married women through composition effect of residence, religion, educational status, occupational status, birth order, number of living children, ideal number of children, history of abortion, media exposure, and media of exposure and wealth index and actual changes due to a change in health behavior (basic effect - the regression intercept is $\alpha$ when $\mathrm{x}=0$ ); and variation of the proportion of modern contraceptive use by exposure variables $(\beta)$, and the residual effect of other variables not considered as the error term $(\mu)$. 


$$
\Delta C=\left[\sum \bar{c}_{j} * \Delta w_{j}\right]+\left[\sum \bar{w}_{j} * \Delta \alpha\right]+\left[\sum \bar{w}_{j} * x \Delta \beta\right]+\left[\sum \bar{w}_{j} * x \Delta \mu\right]
$$

Where $\Delta$ denotes change, $\bar{c}=$ percentage of modern contraceptive use, $\bar{c}_{j}=$ arithmetic mean of percentage of modern contraceptive use for the $\mathrm{j}^{\text {th }}$ category of the exposure variable, $\bar{w}_{j}=$ arithmetic mean of the population structure for the $\mathrm{j}^{\text {th }}$ category of the exposure variable, $\Delta w_{j}=$ change in population structure expressed as a fraction for the jth category of the exposure variable, and, $\mathrm{x}=$ the level of an exposure variable.

\section{Results}

\section{Socio-demographic characteristics}

In this study, the higher proportions $(21.8 \%, 22.9 \%, 24.3 \%$ and $22.8 \%$ in EDHS 2000, 2005, 2011 and 2016, respectively) of study subjects were in the age group of 25-29 years. Participants who had Orthodox Christian and Muslim religion accounted for a major number in all surveys. More than two-thirds of the participants were from rural residents. Nearly half of participants were taken from three regions (Oromia, Amhara and southern nation, nationality and people (SNNP)). More than half of women in the four consecutive surveys had no formal education. Around two-thirds of women had one up to five living children. The poorest wealth index accounted 23.8\%, 26.7\% and 29.6\% in 2005, 2011 and 2016, respectively (Table 1).

\section{The trend in modern contraceptive use}

Modern contraceptive use was steadily increased from $6 \%$ in 2000 to $35 \%$ in 2016 . The trend period was classified into three phases, 2000-2005, 2005-2011 and 2011-2016 to observe the change over time. The highest change in modern contraceptive use was in the second phase of the trend with a $13.4 \%$ change (Fgure1).

The trends in modern contraceptive use by currently married women revealed variation based on their characteristics. Major increment in modern contraceptive use was observed in the age ranges from 20-24 and 25-29, which accounted for $33 \%$ and $32 \%$, respectively. The largest increase in modern contraceptive use was seen in the second phase (2005-2011) of among protestant and orthodox Christian followers 16\% and 15\% correspondingly. In urban residents, 
steadily increment was noticed from EDHS 2000 to 2011 (28\% in 2000, $42 \%$ in 2005 and $49 \%$ in 2011). Amhara (40\%), SNNP (35\%) and Tigray (26\%) regions had the highest overall change in modern contraceptive use from 2000 to 2016 (Table 2). Modern contraceptive use in Addis Ababa (50\%), Amhara (47\%) and SNNP (40\%) showed the highest percentage during the 2016 EDHS report (Figure 2).

Concerning to the ideal number of children, variation was observed over time. The number of ideal children classified as 1-3 (42\%) and 4-6(32\%) accounted for the highest percentages. Women who had media of exposure were used modern contraceptives as compared to nonexposed (Table 3).

\section{Multiple logistic regression analysis}

In binary logistic regression religion, residence, women education, partners education, women's occupation, partners' occupation, birth order, head of household, number of living children, media of exposure and wealth index were candidate variables for multiple logistic regression. Finally, in multiple logistic regression analyses, women's occupation, birth order, the ideal number of children and wealth index had a significant association with modern contraceptive use almost in all EDHS surveys (Table 4).

\section{Decomposition of change in modern contraceptive use}

\section{Difference due to characteristics}

The overall decomposition change in modern contraceptive use among married women was 8.3 $\%$ (2000 to 2016); due to differences in characteristics. Also, there were differences in characteristics on the use of modern contraceptives across the three phases; from 2000 to 2005 and 2005 to 2011 increased by $14 \%$ and $8.7 \%$ respectively, whereas, from 2011 to 2016 decreased by $29 \%$.

Regarding compositional factors, in the first phase, a significant contribution to the change in modern contraceptive use was associated with both women's and partners' education, partners' occupation and media of exposure. Education is a significant variable for use of modern contraceptives. Therefore, an increase in the composition of women's and partners' completion of primary and above education over the survey period revealed a significant contribution to the change in modern contraceptive use (Table 5). 
In the second phase (2005-2011) of the survey, religion, residence, women's and partners' education, media of exposure and wealth index had the highest contribution for a change in modern contraceptive use. Women living in urban residence $(2.7 \%)$ had a higher contribution for a change compared to counterpart. The other significant factor that affected the use of modern contraceptive use was the media of exposure, with $10 \%$ of the contribution to the change.

In the third phase (2011-2016) of the survey, religion, women's and partners' education, women's and partners' occupation, head of the household, number of living children, media of exposure and wealth index were statistically significant variables for the change in modern contraceptive use. The richest women had the highest $(4 \%)$ contribution to this change as compared to the poorest women. Also, women who worked on agriculture had a change in modern contraceptive use negatively by $21 \%$.

For the final phase (2000-2016), religion, residence, women's and partners' education, women's and partners' occupation, head of household, history of abortion and media of exposure had a significant contribution to the change in modern contraceptive use. Protestant women had contributed by $4 \%$ for the change, however, Orthodox Christian women decreased by $9 \%$. Women who had a history of abortion had about $3 \%$ contributions to the change in modern contraceptive use.

\section{Difference due to coefficients}

The differences in effects accounted for $86 \%$ of the observed changes in the use of modern contraceptives in phase I (from 2000 to 2005). In phase II (2005-2011) the difference effects were $91 \%$ among women using the modern contraceptive. Similarly, in phase IV (2000-2016) the observed difference was $92 \%$.

Other things being equal, in phase I, above half (52\%) of the rise in modern contraceptive use in the last fifteen years was due to a change in modern contraceptive use behavior among parterre's occupation of agriculture. Similarly, in phase II, about $17 \%$ of the difference was accounted for due to a change in modern contraceptive use behavior among women who had 1-5 numbers of children. Regarding phase III, the difference effects increased in the use of modern contraceptives, about $46 \%$ was by women who desired to have children from four to six. In 
phase IV, after controlling compositional changes, the effect of change in the use of modern contraceptives was increased by $26 \%$ due to partners who had agricultural occupation (Table 5).

\section{Discussion}

The purpose of this study was to investigate the overall changes increased in modern contraceptive use and to determine the difference effects increased in the use of modern contraceptive from 2000 to 2016 EDHS data. Our study showed that the trend of modern contraceptive use over the last fifteen years was increased by $29 \%$ ( $6 \%$ in 2000 and $35 \%$ in 2016). Data analyzed from performance monitoring and accountability 2020 surveys in nine settings in eight countries in sub-Saharan Africa (26) presented that the trends of contraceptive use have increased among currently married women and Ethiopia was one of the countries included in the survey. According to their report, the prevalence of modern contraceptive use was almost a similar increment to the current study. This very rapid increase in the prevalence of cMRP mainly due to the rapid strengthening of family planning programs and. The improvements in family planning programs are directly traceable to increases in government actions including a stronger commitment from political leaders and increased funding(27). additionally, improvements in health, education, and socioeconomic factors can also catalyze fertility reduction in the region and making improvements in child survival and women's education have the greatest potential for reducing fertility $(28,29)$.

The Ethiopian DHS surveys have been a frequently used source for national, in some special cases subnational, estimates of mCPR. The highest overall change in modern contraceptive use from 2000 to 2016 was revealed in Amhara (40\%), SNNP (35\%) and Tigray (26\%) regions. Also, modern contraceptive use in the Somali region remained below $5 \%$ during the four EDHS surveys. This finding is consistent with the study conducted in sub-Saharan African countries(30).

In this study, the overall decomposition change in modern contraceptive use due to difference in characteristics among married women was low (8\%) as compared to the previous study conducted in Ethiopia, where two-thirds of the change in modern contraceptive use was due to difference in the effects of characteristics (15). This difference may be accounted for due to the age variation in the sampled population (15-49 years in our study versus 15-24 years in the 
previous study). However, when we compared the specific age groups 15-24 years of our study population with the previous one, the change attributed for the use of modern contraceptive was almost comparable finding, where the overall change in this group was 62\% (15-19 years, 29\% and $20-25$ years, $33 \%$ ).

In this study, changes occurred in the relationship between residence and mCPR use in decomposition analysis. This showed that the use of modern contraceptives was declined over time (5\%). This effect was seen among married women due to changes in modern contraceptive use behavior of rural residence. This finding is consistent with a study conducted in Ethiopia, and Pakistan showed that being rural residences were to use modern contraceptives had rapid change due to behavioral changes of the population $(15,31)$.

Modern contraceptive use was positively associated with both partners" and women's education. Women who had primary and above educational attainment have consistently increased in the use of modern contraceptives in the last fifteen years. Similarly, studies showed that females' education of primary and above educational status have highly significant effects to increase contraceptive prevalence $(27,32-35)$.

The other significant factor that affected the use of modern contraceptive use was the media of exposure, with $10 \%$ of the contribution to the change. This finding is in line with other studies in Pakistan(36) and Sub-Saharan African countries (37, 38). Women who were exposed to family planning messages through the mass media were more likely to use modern contraceptive methods. In contrast, a study conducted in Senegal showed that there was a positive but nonsignificant association between media exposure and the use of a modern contraceptive method. The possible reason might be mass media are not reaching poorer, less-educated and rural women (39).

Despite increases in national averages, the use of modern contraception by the poor remains low. The overall change of modern contraceptive use among women in the poorest wealth index ( 9 $\%)$ was lower than the richest group (47\%). In addition, in the decomposition analysis, the richest women had the highest (4\%) contribution to this change as compared to the poorest women. The finding is consistent with the study conducted in developing countries $(37,38)$. 
This could be due to income differences and might result in a higher gap in the use of modern contraceptives.

The strength of this study is that the sample size was large and included large enumeration areas to increase the precision of the findings. This study has also included all EDHS surveys, which enable to compare the results across the surveys. We have also used a multivariate decomposition analysis technique that shows a change in characteristics of modern contraceptive use and the effects of change in population behavior.

This study has some limitations. The first limitation was using secondary data sources and some important variables were missed in the analysis such as side effects of contraceptives. The other limitation was the lack of wealth index in the 2000 EDHS survey. This made the obstacle to understand the effect of socio-economic status on the use of modern contraceptives. furthermore, the surveys were not assessed women's perception towards family planning.

\section{Conclusion}

The trend of modern contraceptive use was steadily increased for the last 15 years. There are variations in $\mathrm{mCPR}$ across the regions of Ethiopia. The highest modern contraceptive use was observed in Addis Ababa, whereas the lowest rate has seen in the Somalia region. Although the utilization of modern contraceptives increased by currently married women, the proportion was less than that of the national target. In general, contraceptive use changes in the compositional characteristics and health behavior of the population are driven by the residence, women and partners' education, head of the household, media exposure and wealth Index.

Government and non-governmental organizations should empower women who are in the lower wealth index and no formal education to enhance the use of modern contraceptives. Further work should be done to promote the use of modern family planning methods through mainstream media. 


\author{
Abbreviations \\ DHS=Demographic and Health Survey \\ EDHS=Ethiopian Demographic and Health Survey \\ $\mathrm{mCPR}=$ Modern Contraceptive Prevalence Rate \\ SNNP= South Nation Nationality and People \\ TFR $=$ Total Fertility Rate

\section{Declarations}

\title{
Ethics approval and consent to participate
}

The authors have submitted a proposal to DHS Program/ICF International and permission was obtained to use the data for this study. The DHS Program authorized data access, and data were used merely for this study.

Consent for publication: not applicable

Availability of data and materials:

The datasets generated and/or analyzed during the current study are available in:

https://dhsprogram.com/

\section{Competing interests}

The authors declare that they have no competing interests

\section{Funding}

No founding used for this study

\section{Authors' contributions}

EWM and DAZ have participated in the conception, data management, and analysis, manuscript writing up. HM was participated in statistical analysis and manuscript writing up. All authors are read and approved the final manuscript.

\section{Acknowledgments}

We would like to acknowledge the DHS program for allowing the dataset to use. 


\section{References}

1. United Nations Department of Economic Social Affairs Population Division. World Family Planning 2017.

2. DESA U. United Nations Department of Economic and Social Affairs/Population Division (2009b): World Population Prospects: The 2008 Revision. Internet: http://esa un org/unpp (gelesen am 16. 2010.

3. Sedgh G, Ashford LS, Hussain R. Unmet need for contraception in developing countries: examining Women's reasons for not using a method. New York: Guttmacher Institute. 2016;2:2015-6.

4. ONU. Trends in contraceptive use worldwide 2015. United Nations Nueva York; 2015.

5. Cahill N, Sonneveldt E, Stover J, Weinberger M, Williamson J, Wei C, et al. Modern contraceptive use, unmet need, and demand satisfied among women of reproductive age who are married or in a union in the focus countries of the Family Planning 2020 initiative: a systematic analysis using the Family Planning Estimation Tool. The Lancet. 2018;391(10123):870-82.

6. USAID A. Three successful Sub-Saharan Africa family planning programs: lessons for meeting the MDGs. Washington DC: USAID. 2012.

7. CSA I. Central statistical agency (CSA)[Ethiopia] and ICF. Ethiopia demographic and health survey, Addis Ababa, Ethiopia and Calverton, Maryland, USA. 2016.

8. Ethiopian Public Health Institute (EPHI), ICF. Ethiopia Mini Demographic and Health Survey 2019: Key Indicators. Ethiopia: Rockville, Maryland, USA, 2019.

9. FMoH E. Health Sector Transformation Plan. HSTP 2015/16-2019/20. August, 2015.

10. UNFPA A. Decade of Change in Contraceptive Use in Ethiopia. Depth Analysis of the EDHS 20002011. 2012.

11. Lakew Y, Reda AA, Tamene H, Benedict S, Deribe K. Geographical variation and factors influencing modern contraceptive use among married women in Ethiopia: evidence from a national population based survey. Reproductive health. 2013;10(1):52.

12. Seyife A, Fisseha G, Yebyo H, Gidey G, Gerensea H. Utilization of modern contraceptives and predictors among women in Shimelba refugee camp, Northern Ethiopia. PloS one. 2019;14(3):e0212262.

13. Kebede A, Abaya SG, Merdassa E, Bekuma TT. Factors affecting demand for modern contraceptives among currently married reproductive age women in rural Kebeles of Nunu Kumba district, Oromia, Ethiopia. Contracept Reprod Med. 2019;4:21.

14. Bakibinga P, Matanda D, Kisia L, Mutombo N. Factors associated with use of injectables, longacting and permanent contraceptive methods (iLAPMs) among married women in Zambia: analysis of demographic and health surveys, 1992-2014. Reproductive health. 2019;16(1):78.

15. Worku AG, Tessema GA, Zeleke AA. Trends of modern contraceptive use among young married women based on the 2000, 2005, and 2011 Ethiopian Demographic and Health Surveys: a multivariate decomposition analysis. PloS one. 2015;10(1):e0116525.

16. Shiferaw S, Abdullah M, Mekonnen Y, Maiga A, Akinyemi A, Amouzou A, et al. Trends in contraceptive use and distribution of births with demographic risk factors in Ethiopia: a sub-national analysis. Global health action. 2015;8:29720.

17. Measure DHS. Ethiopia demography health survey. 2000.

18. Macro O. Ethiopia demographic and health survey. Measure DHS. 2005.

19. Central Statistical Agency ORCM. Ethiopia Demographic and Health Survey (DHS) 2011. CSA and ORC Macro Addis Ababa and Calverton; 2012.

20. Croft TN, Marshall AM, Allen CK. Guide to DHS statistics. Rockville, Maryland, USA: ICF. 2018.

21. Jann B. The Blinder-Oaxaca decomposition for linear regression models. The Stata Journal. 2008;8(4):453-79.

22. Powers DA, Yoshioka H, Yun M-S. mvdcmp: Multivariate decomposition for nonlinear response models. The Stata Journal. 2011;11(4):556-76. 
23. Central Statistical Authority. Ethiopia demographic and health survey 2000.

24. CSA-Ethiopia I. International: Ethiopia Demographic and Health Survey 2011. Central Statistical Agency of Ethiopia and ICF International Addis Ababa, Ethiopia and Calverton, Maryland, USA. 2012.

25. Central Statistical Agency (CSA) [Ethiopia], ICF. Ethiopia Demographic and Health Survey 2016. Addis Ababa, Ethiopia, and Rockville, Maryland, USA: 2016.

26. Ahmed S, Choi Y, Rimon JG, Alzouma S, Gichangi P, Guiella G, et al. Trends in contraceptive prevalence rates in sub-Saharan Africa since the 2012 London Summit on Family Planning: results from repeated cross-sectional surveys. The Lancet Global Health. 2019;7(7):e904-e11.

27. Bongaarts J, Hardee K. Trends in contraceptive prevalence in Sub-Saharan Africa: the roles of family planning programs and education. African journal of reproductive health. 2019;23(3):96-105.

28. Caldwell JC, I. O. Orubuloye, and P. Caldwell. . "Fertility Decline in Africa: A New Type of Transition?" Population and Development Review 1992;18(2):211-42.

29. Mona Sharan SA, John May, and Agnes Soucat,. Family Planning Trends in Sub-Saharan Africa: Progress, Prospects, and Lessons Learned.

30. Li Q, Louis TA, Liu L, Wang C, Tsui AO. Subnational estimation of modern contraceptive prevalence in five sub-Saharan African countries: a Bayesian hierarchical approach. BMC public health. 2019;19(1):216.

31. S CWaA. Changes contraceptive use and method mix in Pakistan:1990-1991 to 2006-2007. Health policy and planning. 2012;27:166-74.

32. Asekun-Olarinmoye E, Adebimpe W, Bamidele J, Odu O, Asekun-Olarinmoye I, Ojofeitimi E. Barriers to use of modern contraceptives among women in an inner city area of Osogbo metropolis, Osun state, Nigeria. International journal of women's health. 2013;5:647.

33. Emina JB, Chirwa T, Kandala N-B. Trend in the use of modern contraception in sub-Saharan Africa: does women's education matter? Contraception. 2014;90(2):154-61.

34. Ajong AB, Njotang PN, Kenfack B, Yakum MN, Mbu ER. Knowledge of women in family planning and future desire to use contraception: a cross sectional survey in Urban Cameroon. BMC research notes. 2016;9(1):347.

35. Medhanyie A, Spigt M, Kifle Y, Schaay N, Sanders D, Blanco R, et al. The role of health extension workers in improving utilization of maternal health services in rural areas in Ethiopia: a cross sectional study. BMC health services research. 2012;12(1):352.

36. Carton TW, Agha S. Changes in contraceptive use and method mix in Pakistan: 1990-91 to 200607. Health policy and planning. 2012;27(2):166-74.

37. Babalola S, Figueroa ME, Krenn S. Association of Mass Media Communication with Contraceptive Use in Sub-Saharan Africa: A Meta-Analysis of Demographic and Health Surveys. Journal of health communication. 2017;22(11):885-95.

38. Adedini SA, Omisakin OA, Somefun OD. Trends, patterns and determinants of long-acting reversible methods of contraception among women in sub-Saharan Africa. PloS one.

2019;14(6):e0217574.

39. Jacobs J, Marino M, Edelman A, Jensen J, Darney B. Mass media exposure and modern contraceptive use among married West African adolescents. The European journal of contraception \& reproductive health care : the official journal of the European Society of Contraception. 2017;22(6):43949. 


\section{Tables' legend}

Table 1: Percentage distribution of socio-demographic characteristics of married women age 1549 years (EDHS 2000, 2005, 2011 and 2016)

Table 2: Trends of current modern contraceptive use among married women from EDHS 2000 to 2016

Table 3: percentage distribution of fertility preference and media exposure among currently married women from 2000 to 2016

Table 4: Binary and multiple logistic regression analysis in modern contraceptive use among currently married women in Ethiopia

Table 5: Decomposition of change due to characteristics (E) and coefficient (C) difference in modern contraceptive use among married women in Ethiopia, 2000-2016.

\section{Figures' legend}

Figure 1: Trend of modern contraceptive use among married women in Ethiopia, EDHS 2000 to 2016.

Figure 2: Trend of modern contraceptive use across the regions in Ethiopia from 2000 to 2016. 
Figures

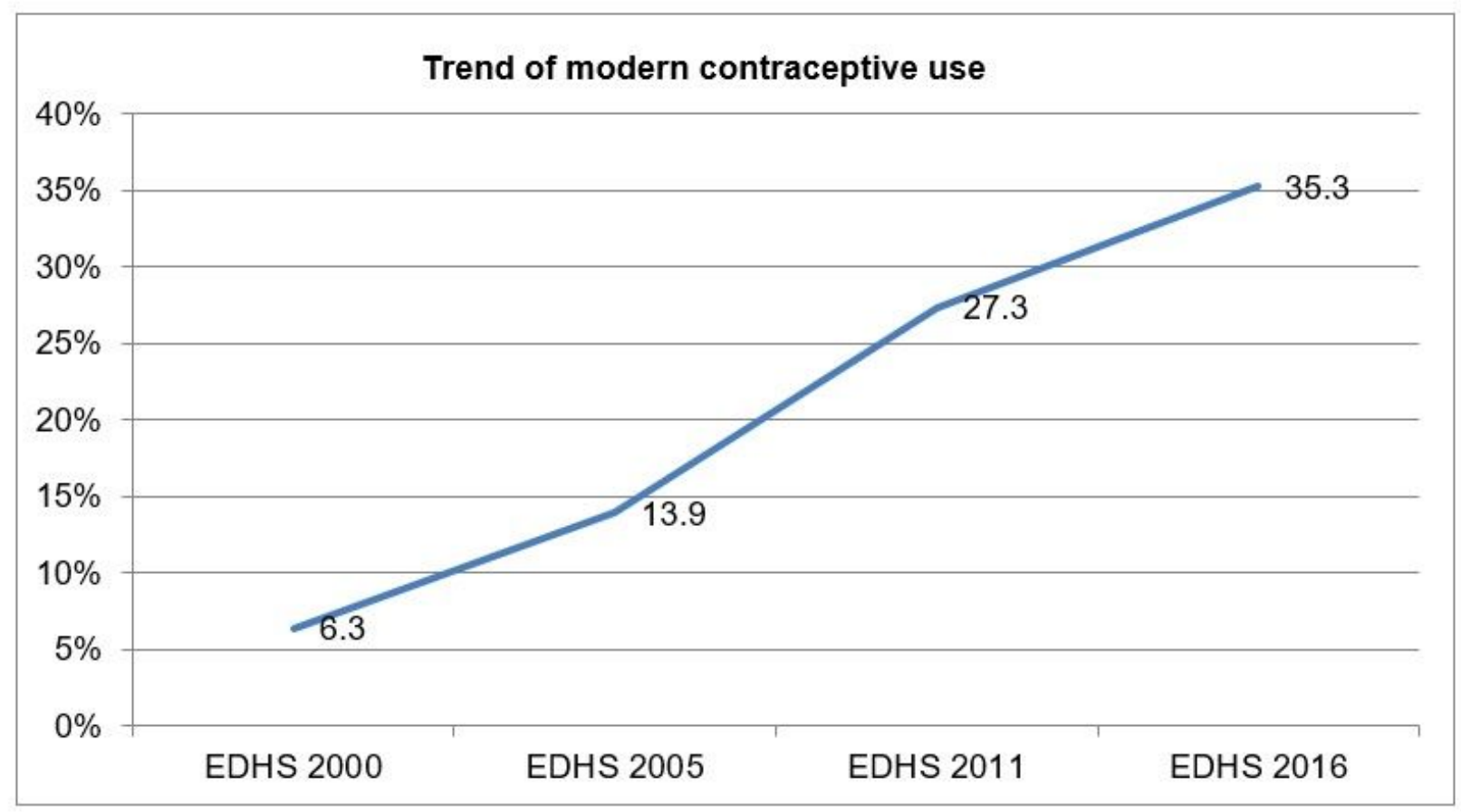

Figure 1

Trend of modern contraceptive use among married women in Ethiopia, EDHS 2000 to 2016.

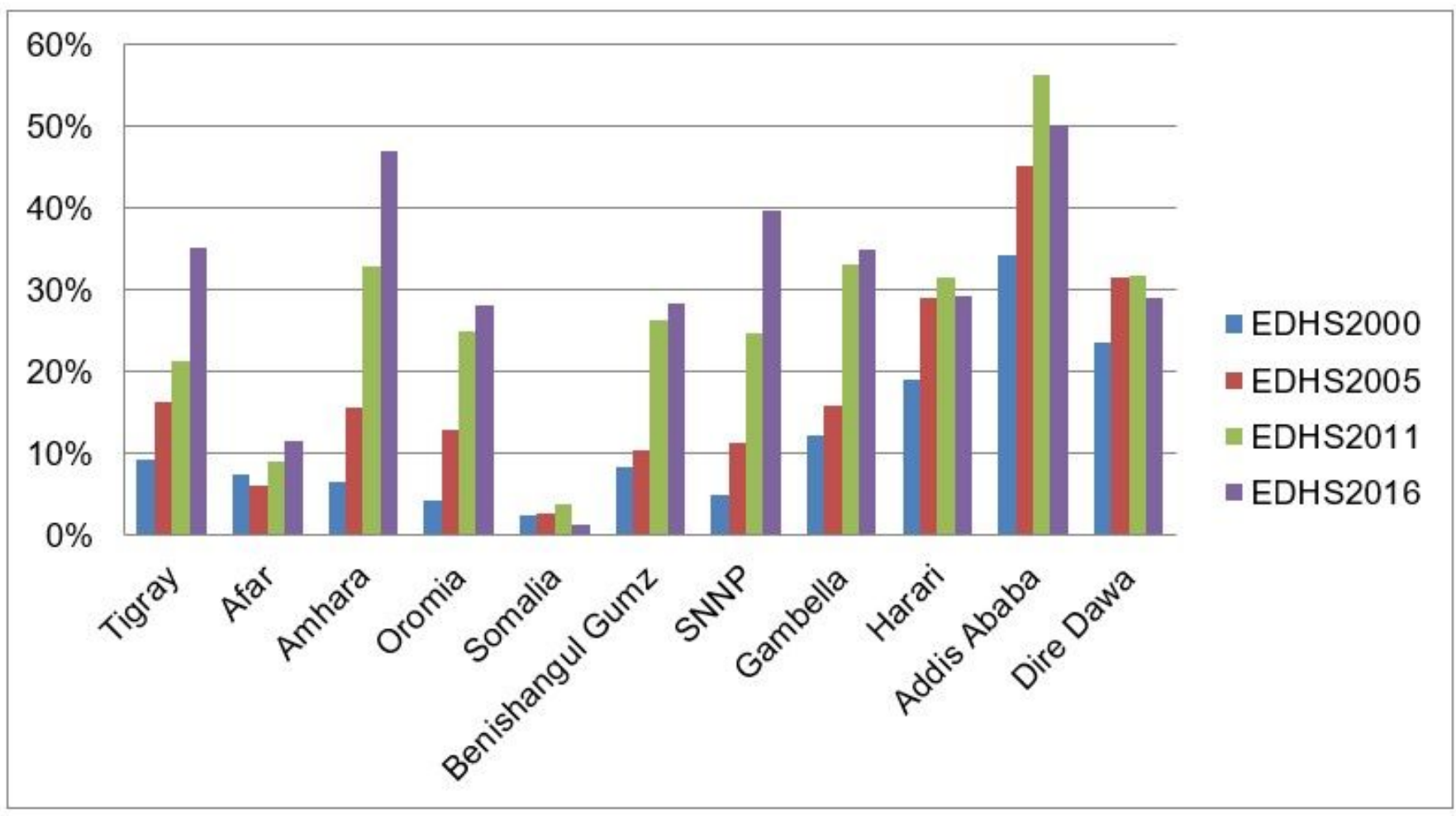


Figure 2

Trend of modern contraceptive use across the regions in Ethiopia from 2000 to 2016. 